\title{
The Botanical Extract Feverfew PFE Reduces DNA Damage and Induces DNA Repair Processes
}

\author{
Michael D. Southall, Simarna Kaur and Khalid Mahmood \\ The Johnson \& Johnson Skin Research Center, CPPW, \\ a division of Johnson $\mathcal{E}$ Johnson Consumer Companies, Inc. Skillman, New Jersey,
}

USA

\section{Introduction}

Our skin is equipped with specialized cells and mechanisms that defend our bodies against pathogens, heat, and water loss. Today, our skin is exposed to increased environmental stress including solar ultraviolet radiation (which results in direct and indirect DNA damage) and atmospheric pollutants. Ozone depletion from the earth's atmosphere as well as expanding industrial processes has led to increased exposure to pollutants including pesticides and cigarette smoke. While UV radiation, and in particular its UV-B component (280-315 nm), has several health benefits (including production of vitamin $\mathrm{D}_{3}$ ) (Reichrath, 2008) continuous exposure is the primary source of UV-induced DNA damage.

The sun produces UV radiation classified into three broad bands. The highest energy UV-C $(100-280 \mathrm{~nm})$ radiation is largely absorbed by the earth's atmosphere and thus does not affect humans. Meanwhile, the UV-B component is partially absorbed by the atmosphere and UV-A (315-400 $\mathrm{nm})$ is primarily unabsorbed. While lower energy UV-A radiation penetrates beyond the epidermis, higher energy UV-B radiation primarily affects the outermost epidermal layer of skin.

Harm to the body's barrier can lead to DNA mutation or DNA replication inhibition in the skin and eyes (cataracts) and may lead to broader immunosuppression (Britt, 1995). The most serious skin cancer (malignant melanoma) occurs when excitation of a chromophore leads to either direct reaction of the excited molecule with DNA or in the production of a free radical which may also react with DNA. Since the body produces oxygen free radicals (ROS) as part of normal metabolism (during ATP production), it is able to combat oxidative stress through endogenous antioxidants.

The body's protective system, however, may become overwhelmed and compromised by environmental factors, age, or disease. Aging leads not only to increased total exposure but also to a decrease in production of endogenous antioxidants (enzymes and vitamins) and an increased risk of DNA damage. Oxidative stress can also lead to damage to other cellular components including lipids and proteins. A naturally-derived method to enhance protection against environmental factors that eventually overwhelm the body's defense mechanisms is discussed. Another major risk of UV radiation is oxidative damage to lipids (peroxidation) and proteins. Cell membranes, which are composed of lipids, are especially 
prone to the damaging effect of free radicals (Sen, et al., 2010). Prolonged oxidative stress to the lipid bilayer can lead to membrane rupture and apoptosis. Lipid peroxidation is, in fact, used as a marker of oxidative stress since the lipid membrane is easily attacked by free radicals.

Cellular DNA damage caused by UV radiation may be classified into two components. The first is that caused by an immediate photochemical reaction (direct) while the other is caused by the formation of ROS (indirect). Direct damage (through direct UV absorption) results primarily in the DNA product cyclobutane-pyrimidine dimer (CPD) (Farage, et al., 2010). On the other hand, indirect damage (through ROS formation) causes DNA mutation due to a replication error induced by modified guanine base (8-oxo-guanine). Direct UV absorption also leads to the formation of 8-oxo-guanine (8oGua) as well as the photoproduct pyrimidine (6-4) pyrimidinone although in proportionally lower amounts.

\section{Free radicals \& ROS}

The negative effect of free radicals may be mitigated by antioxidants primarily through their radical-scavenging ability. These antioxidants stabilize radicals by donating electrons and thus preventing oxidation of DNA or other cellular components. While the body is equipped with its own defense system against reactive oxygen species (ROS) and other free radicals produced in the body, it also relies on external (exogenous) antioxidants including those contained in food. As environmental conditions lead to premature aging, a search for a suitable antioxidant product is vital.

Free radicals cause damage in the body because of their instability and high reactivity. ROS are of particular interest. During aerobic respiration, mitochondrial electron transport results in the formation of a ROS (superoxide) as a by-product. Solar UV radiation also leads to formation of ROS. Oxygen is particularly vulnerable to radical formation due to its electronic configuration with two valence shell unpaired electrons. Thus, there are several types of ROS including superoxide, hydrogen peroxide, nitric oxide, and hydroxyl radical. Free radicals of other atomic species specifically nitrogen are also formed within the body. ROS can potentially react with other cellular entities including DNA which can lead to DNA modification and ultimately bodily harm. The guanine base in DNA is particularly susceptible to attack by ROS formed by solar UV radiation. Oxidation reactions which modify the guanine base may also lead to single-strand breaks in DNA (Held, 2010).

While the effects of oxidative stress on the body vary according to type and duration, cells often halt division (enter $\mathrm{G}_{0}$ phase) and may even undergo apoptosis under severe stress. The general response to oxidative stress is cell cycle arrest through the expression of various inhibitor proteins (such as p21). Nevertheless, ROS also serve useful roles within the body including intracellular and intercellular communication (Held, 2010).

\section{Antioxidants combat oxidative stress}

While broad-spectrum sunscreens which absorb and reflect harmful solar radiation remain the most effective protection against immediate solar UV damage (which result in CPD formation), antioxidants are crucial in combating oxidative stress caused by ROS. Skin's antioxidant system consists of vitamins (vitamins $\mathrm{C}$ and $\mathrm{E}$ ), enzymes (catalase and superoxide dismutase), glutathione, and coenzyme Q10 (CoQ 10$)$. As these antioxidants perform their protective actions and are degraded by ROS, they are reactivated by other 
antioxidants. Because several types of ROS may be formed through environmental insult, several types of antioxidants are produced in the skin. Thus antioxidants come in various forms (vitamins, enzymes, etc.) and may be either lipophilic or hydrophilic to function in a variety of areas.

\section{DNA repair mechanism in plants}

In plants, UV radiation-induced DNA damage can lead to DNA replication inhibition. Although plants exhibit mechanisms by which they are able tolerate some DNA damage, DNA mutation can still lead to transcription and replication blocks. Since plants, like humans, are subjected to oxidative stress (including that induced by UV radiation), an investigation into the evolutionary response by plants to this stress may allow us to apply these findings in a clinical setting.

By their nature, plants are subjected to solar UV radiation indiscriminately. They must necessarily, then, possess inherent methods to prevent and repair DNA damage. While plants are better able to absorb the high energy UV radiation through various photonabsorbing structures, they are still at high risk for oxidative modification of DNA. DNA repair mechanisms in plants such as Arabidopsis thaliana have been investigated and serve as a foundation for the search of a botanical extract that can effectively combat UV-induced DNA damage.

Repair mechanisms increase the likelihood of the accurate transmission of genetic information from parent to daughter cell and thus the survival of the species. Although plants have developed methods to minimize the toxic effects of DNA damage including DNA translesion synthesis and recombination (Schmitz-Hoerner and Weissenbock, 2003), they also have active repair pathways. These pathways include photoreactivation (via photolyase), nucleotide excision repair, base excision repair, and mismatch repair (Kimura et al., 2004).

Plants and some other organisms are able to use light energy (UV and visible) to reverse DNA damage. The enzyme photolyase binds to CPDs and via photoreactivation removes UV-induced lesions. Additionally, excision repair pathways work by replacing damaged DNA with new nucleotides. Base excision repair (BER) employs various DNA glycosylases to remove modified DNA. On the other hand, nucleotide excision repair (NER) is essential in solar radiation protection and in repairing a wide range of DNA lesions. A complex array of proteins recognize, bind to, excise, and repair DNA irregularities in both excision repair pathways.

Humans share repair pathways with plants, particularly nucleotide excision repair (NER). NER is essential in removing major damage to DNA which interferes with the genetic code. Due to similarities in DNA damage and repair mechanisms in plants and humans, metabolites produced by plants may provide beneficial effects in humans.

\section{Botanical extracts | Feverfew PFE as an antioxidant}

Feverfew (Tanacetum parthenium) is a plant that has been used as a medicinal herb for centuries throughout Eastern Europe and more recently North America. Traditionally, it was used for its anti-inflammatory properties to treat migraine headaches, fever, and arthritis. Additionally, feverfew has shown to exhibit powerful antioxidant activity. Although feverfew leaves contain skin irritating compounds called parthenolides, 
purification processes are available to create feverfew parthenolide-free extract (Feverfew PFE) which does not produce skin irritation and is free of sensitization potential (Kurtz, et al., 2005).

\subsection{Feverfew PFE reduces UV and external aggression induced reactive oxygen species formation}

Reactive Oxygen Species are produced in skin following UV irradiation and is a major mediator of oxidative damage to the skin (Pathak and Stratton, 1968). Hydrogen Peroxide $\left(\mathrm{H}_{2} \mathrm{O}_{2}\right)$ and peroxyl radicals are produced in skin following UVB irradiation (Stewart et al., 1996) and can induce oxidative damage to DNA and other cellular constituents. Singlet oxygen can be generated from the action of UVA and endogenous photosensitizers, such as porphyrins and flavins (Cadet et al., 1997), which can produce DNA damage. In addition external aggression such as cigarette smoke can induce oxidative stress in human tissues. Cigarette smoke not only contains peroxy radicals but also contains nitric oxide which can facilitate conversion of peroxy radicals into the more highly reactive alkoxy and hydroxy radicals. Exposure to cigarette smoke depletes the intracellular antioxidant thiol glutathione, decreases phagocytic cell chemotaxis, increases epithelial cell permeability and proinflammatory cytokine release, reduces epithelial cell repair processes and can result in cell death (Rahman and MacNee, 1999), (Rusznak et al., 2000).

Feverfew PFE has been shown to directly scavenging a wide range of free radicals, thereby reducing the oxidative damage to skin that can result from the presence of the free radicals. Feverfew PFE had the greatest scavenging activity against ferric radicals, followed by oxygen, hydroxyl, peroxynitrate radicals respectively (Martin et al., 2008). In comparison to the reference antioxidant, Ascorbic acid (Vitamin C), Feverfew PFE has a 5-fold greater scavenging activity for oxygen and hydroxyl radicals than Ascorbic acid, and 3-fold greater scavenging activity for ferric radicals than Ascorbic acid. Feverfew PFE was also 13-fold greater than Ascorbic acid in scavenging the superoxide anion.

Functionally Feverfew PFE was also shown to reduce UV-induced cellular damage in primary human keratinocytes. Exposing normal human keratinocytes to UV increases the production of hydrogen peroxide $\left(\mathrm{H}_{2} \mathrm{O}_{2}\right) \cdot \mathrm{H}_{2} \mathrm{O}_{2}$ production is represented as mean fluorescent units (MFU). The production of hydrogen peroxide occurs during exposure to $\mathrm{UV}$, so that measurements of hydrogen peroxide immediately after UV exposure can detect significant increases in hydrogen peroxide. A dose of $4.2 \mathrm{~kJ} / \mathrm{m}^{2}$ (at $360 \mathrm{~nm}$ ) from a solar simulator increased intracellular hydrogen peroxide by $73 \%$.

Preincubation with Feverfew PFE at concentrations from 3.1 to $100 \mu \mathrm{g} / \mathrm{mL}$ significantly attenuated hydrogen peroxide production in a dose-dependent manner $\left({ }^{*} \mathrm{P}<0.05\right.$ compared with UV exposed vehicle treated control keratinocytes). At concentrations greater than 10 $\mu \mathrm{g} / \mathrm{mL}$ the suppression of hydrogen peroxide production was less than in non-irradiated controls indicating that Feverfew PFE reduced the basal level of hydrogen peroxide present in keratinocytes due to metabolism (Tierney, et al., 2005). The activity of Feverfew PFE reducing oxidative stress in keratinocytes was not limited to UV exposure. Exposure to external aggressors such as cigarette smoke was found to increase free radical formation in keratinocytes which was inhibited by Feverfew PFE in a dose dependent manner at concentrations as low as $6 \mu \mathrm{g} / \mathrm{mL}$. The reduction of oxidative stress in skin cells also helped to preserve the levels of endogenous cellular antioxidants. In cells exposed to cigarette smoke treatment with Feverfew PFE maintained the cellular thiol content at levels similar to 


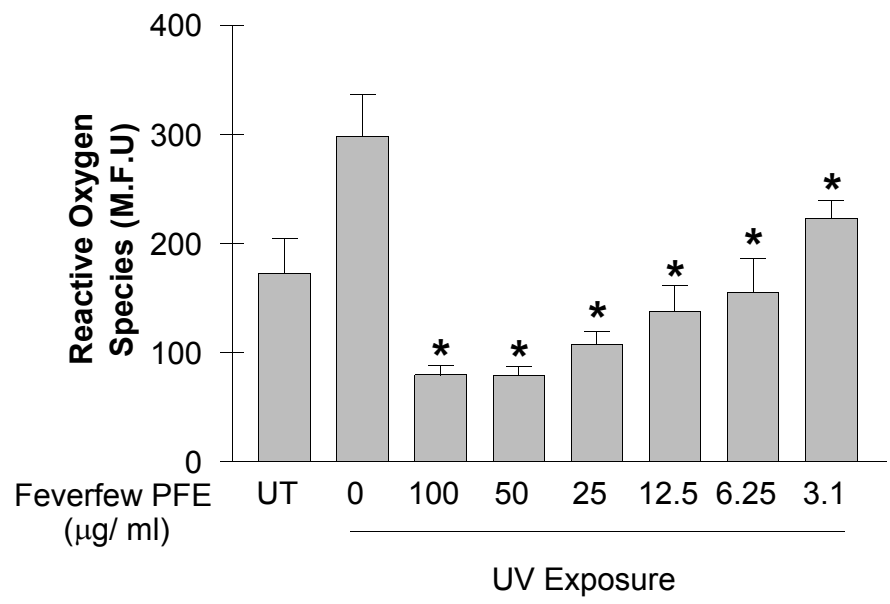

Fig. 1. Feverfew PFE inhibits Reactive Oxygen Species.

those in the no-smoke exposed control (Martin et al., 2008). Through free radicals scavenging activity and preserving endogenous antioxidant levels, Feverfew PFE may protect skin from oxidative stress that could result in DNA damage.

\subsection{Feverfew PFE inhibits cellular inflammation}

UV irradiation has been shown to induce the release of various inflammatory cytokines such as IL-1a, IL-6, TNF- $a$, that are involved in the pathophysiology of UV-induced inflammation (Aubin, 2003). Inflammation has been linked to epithelial skin tumors, and antiinflammatory drugs are being studied for the prevention and treatment of non-melanoma skin cancers (Mueller, 2006).

Feverfew PFE can reduce the release of pro-inflammatory mediators through inhibition of enzymes involved in production and regulation of inflammation. Feverfew PFE directly inhibited the activity of 5-lipoxygenase (5-LOX), phosphodiesterase-3 (PDE3) and phosphodiesterase-4 (PDE4) with IC50 values $11.8 \pm 4.8 \mu \mathrm{g} / \mathrm{ml}, 35.2 \pm 12.3 \mu \mathrm{g} / \mathrm{ml}$ and $20.8 \pm$ $9.4 \mathrm{\mu g} / \mathrm{ml}$ respectively (Martin et al., 2008).

Feverfew PFE also reduced $\mathrm{PGE}_{2}$ secretion from human skin equivalents and inhibited p38 MAP kinase activation in vitro (Martin et al., 2005). Feverfew PFE had no direct effect on COX-2, this indicates the mechanism of inhibiting $\mathrm{PGE}_{2}$ formation may be upstream to COX-2. Human skin equivalents were pretreated with Feverfew PFE and then thoroughly washed prior to UV exposure. In the absence of treatment, UV irradiation induced inflammatory cytokine release. Pretreatment with Feverfew PFE significantly reduced UVinduced cytokine release by more than $60 \%$ over placebo treated control skin equivalents.

Topical application of Feverfew PFE was examined in an investigator blinded, placebocontrolled clinical study for their effect on UV-induced erythema. Subjects were exposed to UVB irradiation of 0.5 to 1.5 MED (Minimal Erythema Dose), followed by daily applications 
of Feverfew PFE. Chromameter, diffused reflectance spectroscopy measurements and independent dermatologist assessment concluded that Feverfew PFE significantly reduced the UV-induced erythema at 24 and 48 hrs after UV exposure (Tierney et al., 2005). This clinical study clearly demonstrates that Feverfew PFE can reduce the skin inflammation and damage resulting from UV exposure.

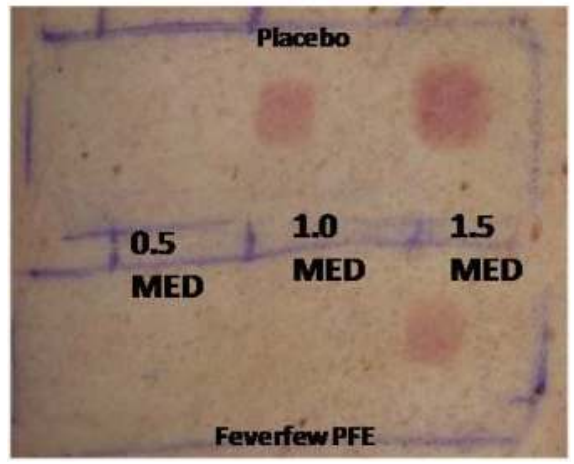

Fig. 2. Feverfew PFE mitigates UV-induced erythema.

\subsection{Feverfew PFE reduces DNA damage}

One of the major adverse effects of UV irradiation is damage to DNA. DNA damage by UVB irradiation results from photochemical reactions consequent to direct absorption of photons by DNA bases. The UV-induced DNA lesions that have been studied in most detail are the cyclobutane pyrimidine dimer (CPD) and the 6-4 pyrimidine-pyrimidone photoproduct (6$4 \mathrm{PP})$ at adjacent pyrimidines (Nakajima et al., 2004). Nuclear DNA strand breaks are produced by incubation of keratinocytes with hydrogen peroxide (Armeni et al., 2001) and hydroxyl radicals, which are generated from hydrogen peroxide through $\mathrm{Fe}^{2+}$-mediated Fenton-type reactions (Stewart et al., 1996).
No UV
UV
UV + Feverfew

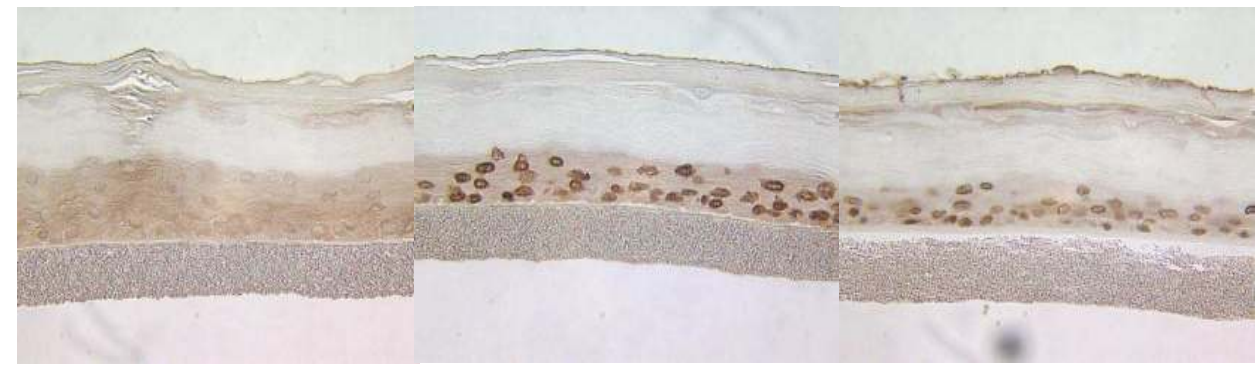

Fig. 3. Treatment with Feverfew PFE inhibits UV-induced T-T dimer formation.

UV light exposure induces a dose dependent increase in Thymine dimer immunostaining of human skin equivalent tissue. Exposure to $65 \mathrm{~kJ} / \mathrm{m}^{2}$ of UV produced a 10-fold increase in T$\mathrm{T}$ dimer formation and $160 \mathrm{~kJ} / \mathrm{m}^{2}$ increased T-T dimers approximately 14-fold. Feverfew 
PFE decreased UV induced TT dimer formation by nearly 50\% compared to UV alone (Martin etal 2008). Thus the antioxidant properties of Feverfew PFE can block the cascade of events taking place between UV irradiation and DNA damage.

In addition to having direct effects on mitigating DNA damage, Feverfew PFE may also aid the DNA repair process via an indirect mechanism, such as induction of the Nrf2/ARE pathway and downstream activation of several genes involved in oxidative stress response.

\section{The NRF2/ARE pathway and its effect on reducing oxidative damage and DNA damage}

\subsection{Antioxidant Response Element (ARE)}

The antioxidant response element is a cis-acting enhancer sequence that mediates transcriptional activation of genes in cells exposed to oxidative stress. It was initially identified in the promoters of the cell detoxification enzymes, GSTA2 (glutathione Stransferase A2) and NQO1 (NADPH: quinone oxidoreductase 1) (Friling et al., 1990; Li and Jaiswal, 1992; Rushmore and Pickett, 1990). The ARE possesses structural and biological features that characterize its unique responsiveness to oxidative stress, and its consensus sequence was identified to be 5'-TGACnnnGC-3' (Rushmore et al., 1991). In addition to being involved in inducible gene expression, the antioxidant response element is also responsible for the low-level basal expression of several genes, and is therefore crucial for maintaining cellular redox homeostasis under a variety of cell conditions. Proteins that are encoded by the ARE include enzymes associated with glutathione biosynthesis (Moinova and Mulcahy, 1998; Wild et al., 1998), redox proteins with active sulfhydryl moieties (Ishii et al., 2000; Kim et al., 2001), and drug-metabolizing enzymes (Favreau and Pickett, 1991; Rushmore and Pickett, 1990). Several of these proteins have an endogenous role in protecting the cells from oxidative damage, for example, enzymes such as GST, NQO1, and HO-1 (heme oxygenase-1) function to detoxify harmful by-products of oxidative stress. Other phase II enzymes induced by ARE activation include aldehyde dehydrogenase, glutathione peroxidase, glutathione transferases, superoxide dismutase, quinone reductase, epoxide hydrolase, UDP-glucuronosyl transferases, and gamma-glutamylcysteine synthetase, etc. The human 8-oxoguanine DNA glycosylase (OGG1) enzyme has also been shown to contain the binding sites for transcription factor Nrf2 in its promoter region (Dhenaut et al., 2000). Human OGG1 functions to remove 8-oxoG, a mutagenic base byproduct which occurs as a result of exposure to reactive oxygen, from damaged DNA and initiates base excision DNA repair.

\subsection{Transcription factor Nrf2}

Transcription factor Nrf2 (Nuclear factor E2-related factor 2) binds to and induces activation of the ARE. Nrf2 was first isolated by an expression cloning procedure using an oligonucleotide containing the NF-E2 DNA binding motif as a probe to screen for closely related proteins (Moi et al., 1994). Nrf2 belongs to the cap-and-collar family of basic regionleucine zipper transcription factors, and is an essential component of the ARE-mediated transcriptional machinery. It has been shown that Nrf2 mediates both the basal and inducible activity of the ARE, and the loss of Nrf2 results in a profound reduction in the enzyme activities of NQO1 and certain GST isoenzymes (Itoh et al., 1997). These observations also correlate well with the ubiquitous expression of Nrf2 at steady-state levels 
in various tissues and cell lines (Nguyen et al., 2004). As a result, the function of Nrf2 and its downstream target genes are vital for protection against cellular damage induced by oxidative stress or chemicals. Several studies have shown that Nrf2 knockout mice having decreased levels of phase II detoxification enzymes and antioxidant proteins are highly sensitive to cytotoxic electrophiles compared to their wild-type littermates (Lee and Johnson, 2004; Leung et al., 2003). The upregulation of protective detoxification and antioxidant genes by Nrf2/ARE pathway can synergistically increase the efficiency of our cellular defense system.

\subsection{Activation of the Nrf2/ARE pathway by oxidative stress}

The induction of several cytoprotective enzymes in response to reactive chemical entities or oxidative stress is regulated at the transcriptional level via activation of Nrf2. This transcriptional response is mediated by the ARE, and is activated in response to $\mathrm{H}_{2} \mathrm{O}_{2}$ (Purdom-Dickinson et al., 2007) and by chemical compounds with the capacity to either undergo redox cycling or be metabolically transformed to a reactive or electrophilic intermediate (Nguyen et al., 2003). Several electrophiles, including diethyl maleate, tertbutylhydroquinone, sulforaphane (Zhang et al., 1992) and curcumin (Balogun et al., 2003) have been shown to induce Nrf2-dependent transcriptional activation of downstream target genes. In addition, several phytochemicals, such as Sulforaphane obtained from cruciferous vegetables (Zhang et al., 1992), Resveratrol (Kode et al., 2008), and Celastrol from the medicinal plant Tripterygium wilfordii (Seo et al.) have also been shown to activate the antioxidant response element. Chemical compounds such as the isothiocyanates and diethyl maleate can directly react with sulfhydryl groups and do not require metabolism. They can mimic an oxidative insult by oxidizing cysteine residues and depleting reduced cellular glutathione $(\mathrm{GSH})$. Elevated levels of reactive oxygen and other electrophilic species followed by a reduced antioxidant capacity can lead to the alteration of the cellular redox status and trigger the transcriptional response mediated by Nrf2/ ARE (Nguyen et al., 2009).

\subsection{Pathways/mechanism that regulate Nrf2/ARE}

The major signaling pathways implicated in the modulation of ARE/Nrf2 activity include mitogen activated protein (MAP) kinases, phosphatidylinositol-3-kinase (PI3 kinase), and Protein kinase $\mathrm{C}$ (PKC). Activation of ERK signaling by sulforaphane and other agents was shown to be involved in ARE/Nrf2 induction (Yu et al., 1999), while p38 MAPK was found to negatively regulate ARE/Nrf2 in certain cell types (Keum et al., 2006; Yu et al., 2000a; Yu et al., 2000b). The PI3 kinase pathway has also been demonstrated to be a key component of ARE/Nrf2 regulation; induction of ARE-driven antioxidant genes by sulforaphane was abrogated by blocking PI3 kinase (Nakaso et al., 2003; Wang et al., 2008). Direct involvement of PKC in Nrf2 phosphorylation and ARE activation has also been established (Huang et al., 2000, 2002; Numazawa et al., 2003).

\subsection{Activation of the Nrf2/ARE pathway by Feverfew PFE}

Human epidermoid KB cells expressing the antioxidant response element promoter were treated with Feverfew PFE or with the well-known ARE-inducing agent Sulforaphane (Zhang et al., 1992) for a period of $24 \mathrm{hr}$. Treatment with Feverfew PFE led to 2-fold activation of the ARE promoter, which was at par with the induction mediated by Sulforaphane. 


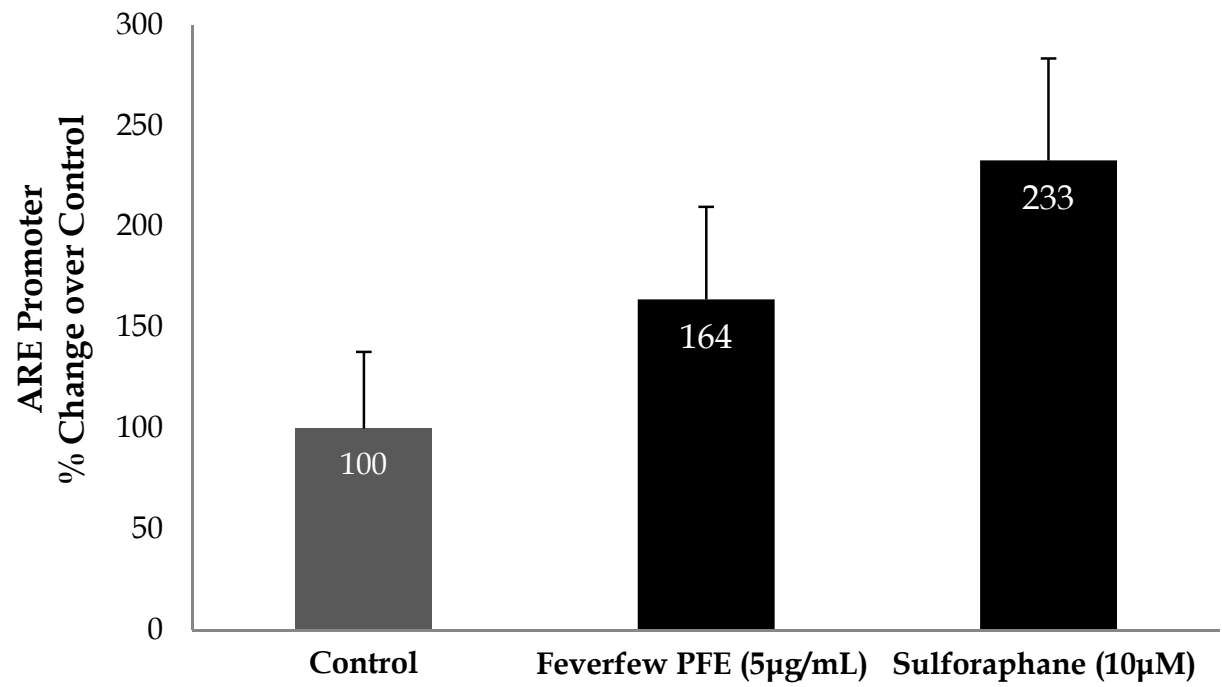

Fig. 4. Feverfew PFE induces activation of the ARE promoter.

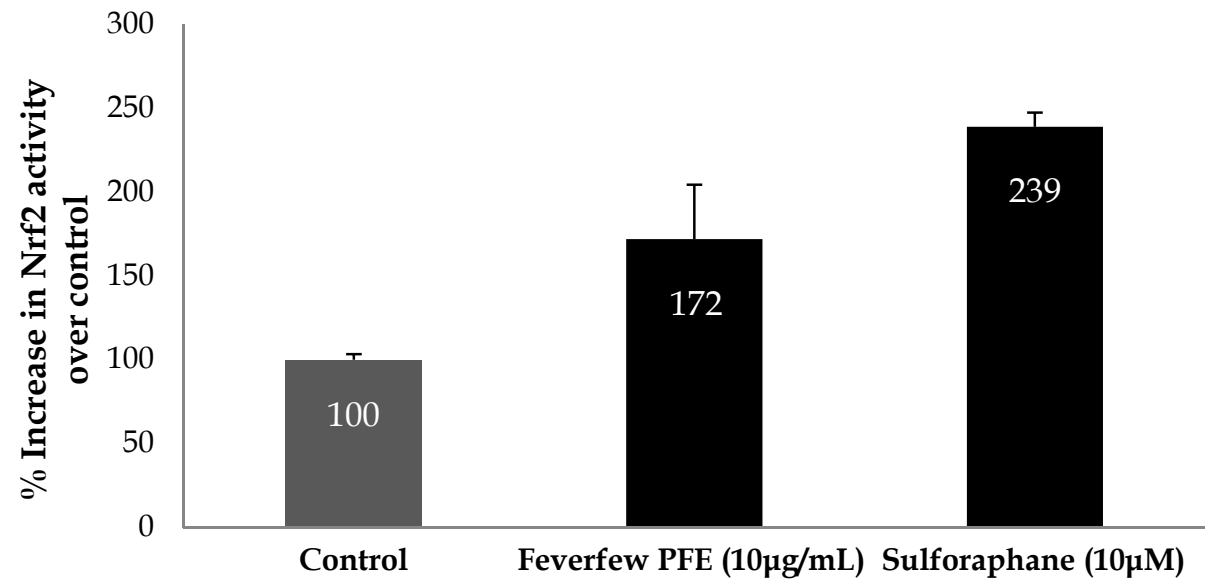

Fig. 5. Feverfew PFE activates the Nrf2 transcription factor.

In order to analyze the effects of Feverfew PFE on the transcription factor, Nrf2, a TransAM ELISA was utilized. Primary human keratinocytes were treated with Feverfew PFE or Sulforaphane for $24 \mathrm{hr}$, following which the nuclear and cytoplasmic cell lysate fractions were separated. Translocation of Nrf2 was analyzed in the nuclear fractions. Feverfew PFE enhanced the nuclear translocation of Nrf2 by more than $70 \%$. 
The downstream functional effects of Nrf2/ARE activation by Feverfew PFE were analyzed by using an Oxidative Stress and Antioxidant Defense PCR array. Human epidermal skin equivalents treated with Feverfew PFE for $24 \mathrm{hr}$ were analyzed using the PCR array. Feverfew PFE led to more than 2-fold increase in the expression of several genes involved in antioxidant defense and oxidative stress. These genes included Lactoperoxidase, an antioxidant-related gene which functions as a natural antibacterial agent, Glutathione Peroxidase which functions to protect the organism from oxidative damage by reducing free hydrogen peroxide to water, inducible Nitric Oxide Synthase-2 involved in superoxide metabolism, and G protein-coupled receptor-156 which is implicated in oxidative stress response.

\begin{tabular}{|l|c|}
\hline Gene & $\begin{array}{c}\text { Fold-increase in Feverfew PFE- } \\
\text { treated sample over vehicle control }\end{array}$ \\
\hline Lactoperoxidase & 2 \\
\hline Glutathione Peroxidase & 2 \\
\hline Inducible-Nitric Oxide synthase-2 (iNOS2) & 3 \\
\hline G-protein coupled Receptor-156 (GPR156) & 3 \\
\hline
\end{tabular}

Table 1. Fevefew PFE leads to induction of antioxidant defense genes.

\section{Feverfew PFE increases expression of DNA repair enzymes}

Skin is continously exposed to numerous aggressors that can cause oxidative DNA damage. The age-related accumulation of somatic damage is worsened by sun exposure, leading to an increased incidence of skin disorders and skin cancer. Chemical entities such as $\mathrm{O}_{2}$; $\mathrm{H}_{2} \mathrm{O}_{2}, \mathrm{OH} \cdot$ are also generated in cells as a result of several endogenous processes including normal cellular metabolism and mitochondrial respiration (Verjat et al., 2000). Some of these chemical species are highly reactive and can interact with DNA, lipids and proteins (Ames and Shigenaga, 1992) causing damage. Oxidative DNA damage can arise through the direct interaction of reactive species with genomic DNA, or via oxidation of DNA precursors in the nucleotide pool (Rai, 2010). One of the major DNA oxidation products formed as a result of such damage is 8-oxo-7,8-dihydro-2'-deoxyguanosine (8-oxo-dG). Mammalian cells have evolved several DNA-repair pathways to remove all the categories of DNA base lesions, relying in particular on DNA excision mechanisms. One of these, nucleotide excision repair, removes bulky adducts and is thus an essential mechanism for correcting UV-induced DNA damage (Sarasin, 1999). The base excision repair pathway corrects small base modifications such as oxidized and alkylated bases (Almeida and Sobol, 2007). The importance of repair mechanisms is demonstrated by the hazardous consequences of genetic defects in DNA repair (Friedberg, 2001).

Feverfew PFE increases the enzymatic activity of DNA repair enzymes in human epidermal keratinocytes. Feverfew PFE directly induced DNA repair via the nucleotide excision repair process resulting in the repair of CPD damage induced by UV exposure. Feverfew PFE also induced the repair of DNA caused by exposure to agents that produce oxidative damage in skin. The chemotherapeutic agent, Cisplatin, and the photodynamic 
agent, Psoralen both induce oxidative stress which can produce DNA damage (Martin et al., 2008). Feverfew PFE induced DNA repair activity in DNA damaged by Cisplatin or Psoralen. Thus Feverfew PFE can activate the endogenous nucleotide excision repair in human epidermal keratinocytes, which could repair DNA damaged by extrinsic or intrinsic ROS formation.

In addition to the direct effects of Feverfew PFE on DNA repair enzymes, activation of the ARE/Nrf2 pathway by Feverfew might also play a crucial role in preventing DNA damage and augmenting DNA repair. Daily exposure to UV, smoke, and other external aggressors leads to the generation of high levels of reactive oxygen species in the body. In order to avoid the deleterious effects of reactive oxidative species, cells have developed different defensive mechanisms including antioxidant molecules such as glutathione, alphatocopherol, vitamins A and C, and enzymes such as superoxide dismutase (SOD) and catalase (Ames et al., 1993; Verjat et al., 2000). When the cellular balance between antioxidants and pro-oxidants is upset, free radicals lead to the formation of lesions in the DNA causing damage, which in most cases is endogenously repaired in the cells by several repair mechanisms. The Nrf2/ARE pathway induces production of a battery of downstream genes that mitigate damage from reactive oxygen species, and aid DNA repair (Villeneuve et al., 2009). It has been shown that activation of Nrf2 generates a glutathione gradient to protect skin from the damaging effects of UVB (Saw et al., Schafer et al.), and reduces UVAinduced apoptosis in fibroblasts (Hirota et al., 2005). Thus, Feverfew PFE may help protect the skin from DNA damage incurred by UV and other environmental aggressors by boosting the cellular antioxidant defense machinery.

\section{Summary and conclusions: The use of botanical extracts for protection from DNA damage and DNA repair}

Skin is under continual assault from a variety of damaging environmental factors such as ultraviolet irradiation and atmospheric pollutants. As organisms age the cumulative damage exceeds the capacity of endogenous antioxidant defenses resulting in oxidative damage. Plants have adapted to chronic exposure to ultraviolet irradiation by producing phytochemicals which can mitigate reactive oxygen species and repair damaged DNA. Botanical extracts such as Feverfew PFE, containing naturally occurring antioxidants can replenish the depleted cutaneous stores and perhaps prevent oxidative stress. Feverfew has been shown to contain chlorogenic acid (Wu et al., 2007), which can activate the Nrf2-ARE pathway (Feng et al., 2005), increase DNA repair enzyme expression (Bernstein et al., 2007), and induce repair of DNA (Huang et al., 2008). Furthermore, chlorogenic acid might be one of several phytochemicals present in Feverfew that could protect from DNA damage and induce the DNA repair process. Through the ability to scavenge free radicals, preserve endogenous antioxidant levels, reduce DNA damage and induce repair of damaged DNA, Feverfew PFE may protect skin from numerous external aggressions encountered daily and reduce the damage to oxidatively challenged skin.

\section{Acknowledgements}

The authors would like to thank Katharine Martin, Neena Tierney, Peter Lyte, Dara Miller, Thierry Oddos, Karien Rodriguez and Dr. Balz Frei (Linus Pauling Institute, Oregon State University) for research and discussions on Feverfew PFE. 


\section{References}

Almeida, K. H., Sobol, R. W., 2007. A unified view of base excision repair: lesion-dependent protein complexes regulated by post-translational modification. DNA Repair (Amst) 6, 695-711.

Ames, B. N., Shigenaga, M. K., 1992. Oxidants are a major contributor to aging. Ann N Y Acad Sci 663, 85-96.

Ames, B. N., Shigenaga, M. K., Hagen, T. M., 1993. Oxidants, antioxidants, and the degenerative diseases of aging. Proc Natl Acad Sci U S A 90, 7915-7922.

Armeni, T., Battino, M., Stronati, A., Pugnaloni, A., Tomassini, G., Rosi, G., Biagini, G., Principato, G., 2001. Total antioxidant capacity and nuclear DNA damage in keratinocytes after exposure to H2O2. Biol Chem 382, 1697-1705.

Aubin, F., 2003. Mechanisms involved in ultraviolet light-induced immunosuppression. Eur J Dermatol 13, 515-523.

Balogun, E., Hoque, M., Gong, P., Killeen, E., Green, C. J., Foresti, R., Alam, J., Motterlini, R., 2003. Curcumin activates the haem oxygenase-1 gene via regulation of Nrf2 and the antioxidant-responsive element. Biochem J 371, 887-895.

Bernstein, H., Crowley-Skillicorn, C., Bernstein, C., Payne, C., Dvorak, K., Garewal, H., 2007. Dietary Compounds that Enhance DNA Repair and their Relevance to Cancer and Aging, In: New research on DNA repair, Landseer, B. R., 99-113, Nova Science Publishers, Inc., 1-60021-385-5, New York.

Cadet, J., Berger, M., Douki, T., Morin, B., Raoul, S., Ravanat, J. L., Spinelli, S., 1997. Effects of UV and visible radiation on DNA-final base damage. Biol Chem 378, 1275-1286.

Dhenaut, A., Boiteux, S., Radicella, J. P., 2000. Characterization of the hOGG1 promoter and its expression during the cell cycle. Mutat Res 461, 109-118.

Favreau, L. V., Pickett, C. B., 1991. Transcriptional regulation of the rat NAD(P)H:quinone reductase gene. Identification of regulatory elements controlling basal level expression and inducible expression by planar aromatic compounds and phenolic antioxidants. J Biol Chem 266, 4556-4561.

Feng, R., Lu, Y., Bowman, L. L., Qian, Y., Castranova, V., Ding, M., 2005. Inhibition of activator protein-1, NF-kappaB, and MAPKs and induction of phase 2 detoxifying enzyme activity by chlorogenic acid. J Biol Chem 280, 27888-27895.

Friedberg, E. C., 2001. How nucleotide excision repair protects against cancer. Nat Rev Cancer 1, 22-33.

Friling, R. S., Bensimon, A., Tichauer, Y., Daniel, V., 1990. Xenobiotic-inducible expression of murine glutathione S-transferase Ya subunit gene is controlled by an electrophileresponsive element. Proc Natl Acad Sci U S A 87, 6258-6262.

Hirota, A., Kawachi, Y., Itoh, K., Nakamura, Y., Xu, X., Banno, T., Takahashi, T., Yamamoto, M., Otsuka, F., 2005. Ultraviolet A irradiation induces NF-E2-related factor 2 activation in dermal fibroblasts: protective role in UVA-induced apoptosis. J Invest Dermatol 124, 825-832.

Huang, H. C., Nguyen, T., Pickett, C. B., 2000. Regulation of the antioxidant response element by protein kinase C-mediated phosphorylation of NF-E2-related factor 2. Proc Natl Acad Sci U S A 97, 12475-12480. 
Huang, H. C., Nguyen, T., Pickett, C. B., 2002. Phosphorylation of Nrf2 at Ser-40 by protein kinase $\mathrm{C}$ regulates antioxidant response element-mediated transcription. J Biol Chem 277, 42769-42774.

Huang, J., Li, T., Chen, Z., Liu, X., Liu, S., 2008. Rapid electrochemical detection of DNA damage and repair with epigallocatechin gallate, chlorogenic acid and ascorbic acid. Electrochemistry Communications 10, 1198-1200.

Ishii, T., Itoh, K., Takahashi, S., Sato, H., Yanagawa, T., Katoh, Y., Bannai, S., Yamamoto, M., 2000. Transcription factor Nrf2 coordinately regulates a group of oxidative stressinducible genes in macrophages. J Biol Chem 275, 16023-16029.

Itoh, K., Chiba, T., Takahashi, S., Ishii, T., Igarashi, K., Katoh, Y., Oyake, T., Hayashi, N., Satoh, K., Hatayama, I., Yamamoto, M., Nabeshima, Y., 1997. An Nrf2/small Maf heterodimer mediates the induction of phase II detoxifying enzyme genes through antioxidant response elements. Biochem Biophys Res Commun 236, 313-322.

Keum, Y. S., Yu, S., Chang, P. P., Yuan, X., Kim, J. H., Xu, C., Han, J., Agarwal, A., Kong, A. N., 2006. Mechanism of action of sulforaphane: inhibition of p38 mitogen-activated protein kinase isoforms contributing to the induction of antioxidant response element-mediated heme oxygenase- 1 in human hepatoma HepG2 cells. Cancer Res 66, 8804-8813.

Kim, Y. C., Masutani, H., Yamaguchi, Y., Itoh, K., Yamamoto, M., Yodoi, J., 2001. Hemininduced activation of the thioredoxin gene by Nrf2. A differential regulation of the antioxidant responsive element by a switch of its binding factors. J Biol Chem 276, 18399-18406.

Kimura, S., Tahira, Y., Ishibashi, T., Mori, Y., Mori, T., Hashimoto, J., Sakaguchi, K., 2004. DNA repair in higher plants; photoreactivation is the major DNA repair pathway in non-proliferating cells while excision repair (nucleotide excision repair and base excision repair) is active in proliferating cells. Nucleic Acids Res 32, 2760-2767.

Kode, A., Rajendrasozhan, S., Caito, S., Yang, S. R., Megson, I. L., Rahman, I., 2008. Resveratrol induces glutathione synthesis by activation of Nrf2 and protects against cigarette smoke-mediated oxidative stress in human lung epithelial cells. Am J Physiol Lung Cell Mol Physiol 294, L478-488.

Lee, J. M., Johnson, J. A., 2004. An important role of Nrf2-ARE pathway in the cellular defense mechanism. J Biochem Mol Biol 37, 139-143.

Leung, L., Kwong, M., Hou, S., Lee, C., Chan, J. Y., 2003. Deficiency of the Nrf1 and Nrf2 transcription factors results in early embryonic lethality and severe oxidative stress. J Biol Chem 278, 48021-48029.

Li, Y., Jaiswal, A. K., 1992. Regulation of human NAD(P)H:quinone oxidoreductase gene. Role of AP1 binding site contained within human antioxidant response element. J Biol Chem 267, 15097-15104.

Martin, K., Sur, R., Liebel, F., Tierney, N., Lyte, P., Garay, M., Oddos, T., Anthonavage, M., Shapiro, S., Southall, M., 2008. Parthenolide-depleted Feverfew (Tanacetum parthenium) protects skin from UV irradiation and external aggression. Arch Dermatol Res 300, 69-80.

Moi, P., Chan, K., Asunis, I., Cao, A., Kan, Y. W., 1994. Isolation of NF-E2-related factor 2 (Nrf2), a NF-E2-like basic leucine zipper transcriptional activator that binds to the 
tandem NF-E2/AP1 repeat of the beta-globin locus control region. Proc Natl Acad Sci U S A 91, 9926-9930.

Moinova, H. R., Mulcahy, R. T., 1998. An electrophile responsive element (EpRE) regulates beta-naphthoflavone induction of the human gamma-glutamylcysteine synthetase regulatory subunit gene. Constitutive expression is mediated by an adjacent AP-1 site. J Biol Chem 273, 14683-14689.

Mueller, M. M., 2006. Inflammation in epithelial skin tumours: old stories and new ideas. Eur J Cancer 42, 735-744.

Nakajima, S., Lan, L., Kanno, S., Takao, M., Yamamoto, K., Eker, A. P., Yasui, A., 2004. UV light-induced DNA damage and tolerance for the survival of nucleotide excision repair-deficient human cells. J Biol Chem 279, 46674-46677.

Nakaso, K., Yano, H., Fukuhara, Y., Takeshima, T., Wada-Isoe, K., Nakashima, K., 2003. $\mathrm{PI} 3 \mathrm{~K}$ is a key molecule in the Nrf2-mediated regulation of antioxidative proteins by hemin in human neuroblastoma cells. FEBS Lett 546, 181-184.

Nguyen, T., Nioi, P., Pickett, C. B., 2009. The Nrf2-antioxidant response element signaling pathway and its activation by oxidative stress. J Biol Chem 284, 13291-13295.

Nguyen, T., Sherratt, P. J., Pickett, C. B., 2003. Regulatory mechanisms controlling gene expression mediated by the antioxidant response element. Annu Rev Pharmacol Toxicol 43, 233-260.

Nguyen, T., Yang, C. S., Pickett, C. B., 2004. The pathways and molecular mechanisms regulating Nrf2 activation in response to chemical stress. Free Radic Biol Med 37, 433-441.

Numazawa, S., Ishikawa, M., Yoshida, A., Tanaka, S., Yoshida, T., 2003. Atypical protein kinase C mediates activation of NF-E2-related factor 2 in response to oxidative stress. Am J Physiol Cell Physiol 285, C334-342.

Pathak, M. A., Stratton, K., 1968. Free radicals in human skin before and after exposure to light. Arch Biochem Biophys 123, 468-476.

Purdom-Dickinson, S. E., Sheveleva, E. V., Sun, H., Chen, Q. M., 2007. Translational control of nrf2 protein in activation of antioxidant response by oxidants. Mol Pharmacol 72, 1074-1081.

Rahman, I., MacNee, W., 1999. Lung glutathione and oxidative stress: implications in cigarette smoke-induced airway disease. Am J Physiol 277, L1067-1088.

Rai, P., Oxidation in the nucleotide pool, the DNA damage response and cellular senescence: Defective bricks build a defective house. Mutat Res 703, 71-81.

Rushmore, T. H., Morton, M. R., Pickett, C. B., 1991. The antioxidant responsive element. Activation by oxidative stress and identification of the DNA consensus sequence required for functional activity. J Biol Chem 266, 11632-11639.

Rushmore, T. H., Pickett, C. B., 1990. Transcriptional regulation of the rat glutathione Stransferase Ya subunit gene. Characterization of a xenobiotic-responsive element controlling inducible expression by phenolic antioxidants. J Biol Chem 265, 1464814653.

Rusznak, C., Mills, P. R., Devalia, J. L., Sapsford, R. J., Davies, R. J., Lozewicz, S., 2000. Effect of cigarette smoke on the permeability and IL-1beta and sICAM-1 release from 
cultured human bronchial epithelial cells of never-smokers, smokers, and patients with chronic obstructive pulmonary disease. Am J Respir Cell Mol Biol 23, 530-536.

Sarasin, A., 1999. The molecular pathways of ultraviolet-induced carcinogenesis. Mutat Res $428,5-10$.

Saw, C. L., Huang, M. T., Liu, Y., Khor, T. O., Conney, A. H., Kong, A. N., Impact of Nrf2 on UVB-induced skin inflammation/photoprotection and photoprotective effect of sulforaphane. Mol Carcinog.

Schafer, M., Dutsch, S., auf dem Keller, U., Werner, S., Nrf2: a central regulator of UV protection in the epidermis. Cell Cycle 9, 2917-2918.

Schmitz-Hoerner, R., Weissenbock, G., 2003. Contribution of phenolic compounds to the UV-B screening capacity of developing barley primary leaves in relation to DNA damage and repair under elevated UV-B levels. Phytochemistry 64, 243-255.

Seo, W. Y., Goh, A. R., Ju, S. M., Song, H. Y., Kwon, D. J., Jun, J. G., Kim, B. C., Choi, S. Y., Park, J., Celastrol induces expression of heme oxygenase-1 through ROS/Nrf2/ ARE signaling in the HaCaT cells. Biochem Biophys Res Commun.

Stewart, M. S., Cameron, G. S., Pence, B. C., 1996. Antioxidant nutrients protect against UVB-induced oxidative damage to DNA of mouse keratinocytes in culture. J Invest Dermatol 106, 1086-1089.

Verjat, T., Dhenaut, A., Radicella, J. P., Araneda, S., 2000. Detection of 8-oxoG DNA glycosylase activity and OGG1 transcripts in the rat CNS. Mutat Res 460, 127138.

Villeneuve, N. F., Sun, Z., Chen, W., Zhang, D. D., 2009. Nrf2 and p21 regulate the fine balance between life and death by controlling ROS levels. Cell Cycle 8, 32553256.

Wang, L., Chen, Y., Sternberg, P., Cai, J., 2008. Essential roles of the PI3 kinase/ Akt pathway in regulating Nrf2-dependent antioxidant functions in the RPE. Invest Ophthalmol Vis Sci 49, 1671-1678.

Wild, A. C., Gipp, J. J., Mulcahy, T., 1998. Overlapping antioxidant response element and PMA response element sequences mediate basal and beta-naphthoflavone-induced expression of the human gamma-glutamylcysteine synthetase catalytic subunit gene. Biochem J 332 ( Pt 2), 373-381.

Wu, C., Chen, F., Wang, X., Wu, Y., Dong, M., He, G., Galyean, R. D., He, L., Huang, G., 2007. Identification of antioxidant phenolic compounds in feverfew (Tanacetum parthenium) by HPLC-ESI-MS/MS and NMR. Phytochem Anal 18, 401-410.

Yu, R., Chen, C., Mo, Y. Y., Hebbar, V., Owuor, E. D., Tan, T. H., Kong, A. N., 2000a. Activation of mitogen-activated protein kinase pathways induces antioxidant response element-mediated gene expression via a Nrf2-dependent mechanism. J Biol Chem 275, 39907-39913.

Yu, R., Lei, W., Mandlekar, S., Weber, M. J., Der, C. J., Wu, J., Kong, A. N., 1999. Role of a mitogen-activated protein kinase pathway in the induction of phase II detoxifying enzymes by chemicals. J Biol Chem 274, 27545-27552.

Yu, R., Mandlekar, S., Lei, W., Fahl, W. E., Tan, T. H., Kong, A. N., 2000b. p38 mitogenactivated protein kinase negatively regulates the induction of phase II drugmetabolizing enzymes that detoxify carcinogens. J Biol Chem 275, 2322-2327. 
Zhang, Y., Talalay, P., Cho, C. G., Posner, G. H., 1992. A major inducer of anticarcinogenic protective enzymes from broccoli: isolation and elucidation of structure. Proc Natl Acad Sci U S A 89, 2399-2403. 


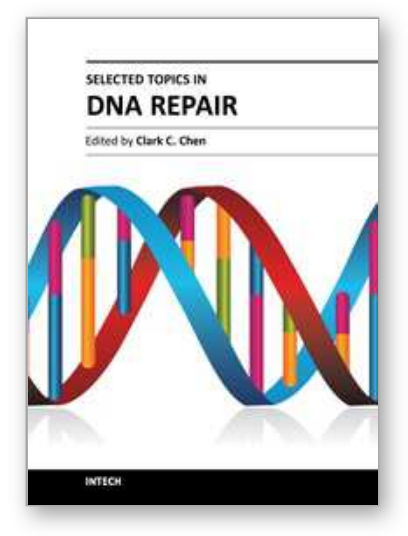

\author{
Selected Topics in DNA Repair \\ Edited by Prof. Clark Chen
}

ISBN 978-953-307-606-5

Hard cover, 572 pages

Publisher InTech

Published online 26, October, 2011

Published in print edition October, 2011

This book is intended for students and scientists working in the field of DNA repair, focusing on a number of topics ranging from DNA damaging agents and mechanistic insights to methods in DNA repair and insights into therapeutic strategies. These topics demonstrate how scientific ideas are developed, tested, dialogued, and matured as it is meant to discuss key concepts in DNA repair. The book should serve as a supplementary text in courses and seminars as well as a general reference for biologists with an interest in DNA repair.

\title{
How to reference
}

In order to correctly reference this scholarly work, feel free to copy and paste the following:

Michael D. Southall, Simarna Kaur and Khalid Mahmood (2011). The Botanical Extract Feverfew PFE Reduces DNA Damage and Induces DNA Repair Processes, Selected Topics in DNA Repair, Prof. Clark Chen (Ed.), ISBN: 978-953-307-606-5, InTech, Available from: http://www.intechopen.com/books/selected-topics-in-dnarepair/the-botanical-extract-feverfew-pfe-reduces-dna-damage-and-induces-dna-repair-processes

\section{INTECH}

open science | open minds

\author{
InTech Europe \\ University Campus STeP Ri \\ Slavka Krautzeka 83/A \\ 51000 Rijeka, Croatia \\ Phone: +385 (51) 770447 \\ Fax: +385 (51) 686166 \\ www.intechopen.com
}

\author{
InTech China \\ Unit 405, Office Block, Hotel Equatorial Shanghai \\ No.65, Yan An Road (West), Shanghai, 200040, China \\ 中国上海市延安西路65号上海国际贵都大饭店办公楼 405 单元 \\ Phone: +86-21-62489820 \\ Fax: $+86-21-62489821$
}


(C) 2011 The Author(s). Licensee IntechOpen. This is an open access article distributed under the terms of the Creative Commons Attribution 3.0 License, which permits unrestricted use, distribution, and reproduction in any medium, provided the original work is properly cited. 